\title{
Translation of DASS 21 into Bangla and validation among medical students
}

\author{
SM Abu Hena Mostafa Alim, ${ }^{1}$ Syed Mahbub-E-Kibria, ${ }^{2}$ Md Jahurul Is $\mid a m,{ }^{3}$ Md Zahir Uddin, ${ }^{4}$ Meherun \\ Nessa, ${ }^{5}$ Md Abdul Wahab, ${ }^{6}$ Md Mesbahul Islam $^{7}$
}

${ }^{1}$ Assistant Professor, Department of Psychiatry, Rajshahi Medical College, Rajshahi, Bangladesh; ${ }^{2}$ Medical Officer, Department of Psychiatry, Khulna Medical College, Khulna, Bangladesh; ${ }^{3}$ Professor, Department of English, Rajshahi University, Rajshahi, Bangladesh; ${ }^{4}$ Assistant Professor (Clinical Psychology), Department of Psychotherapy, National Institute of Mental Health (NIMH), Sher-E-Bangla Nagar, Dhaka, Bangladesh; ${ }^{5}$ Assistant Professor, Department of English, Sher-E-Bangla Agricultural University, Dhaka, Bangladesh; ${ }^{6}$ Professor, Department of Psychiatry, Monno Medical College, Manikganj, Bangladesh; "Clinical Psychologist, Mental Hospital, Pabna, Bangladesh.

Article info
Received: 23 August 2016
Accepted : 26 Sept 2016
Number of tables : 01
Number of figures : 03
Number of refs. : 11
Correspondence:
SM Abu Hena Mostafa Alim
Mobile: +8801711703826,
E-mail: abul458@gmail.com

\section{Article info}

Received: 23 August 2016

Accepted : 26 Sept 2016

Number of tables : 01

Number of figures : 03

\begin{abstract}
Summary:
Standard scale to assess the symptoms of depression, anxiety and stress among MBBS students are essential to take necessary steps to treat or prevent any psychiatric morbidity. But there was no such convenient tool in Bangla to measure the stated symptoms. With an objective to obtain a convenient scale to measure severity of above symptoms, short version of Depression Anxiety Stress Scales (DASS 21) was translated into Bangla and the study was carried out to validate this Bangla version with permission from the author of the original instrument. Two translations and back translations were carried out. A harmonized version was produced after meetings by persons involved in translation process in meetings. After pretesting on ten students and reviewing by panel of experts, finalized Bangla version of DASS 21 (DASS 21 -BV) was obtained. A cross sectional study was carried out among MBBS students of Pabna Medical College, Pabna using purposive sampling technique to validate this scale. They were given both Bangla and English version of the scale 3 to 7 days apart. Analysis was done on 15 samples. Correlation for depression subscale was 0.976, anxiety subscale was 0.917 and stress subscale was 0.931 . Correlation was significant at the 0.01 level (2-tailed). Cronbach's Alpha for Depression, Anxiety and Stress subscales were $0.987,0.957,0.964$ respectively. This Validated Bangla version of DASS 21 can be used to measure severity of depression among medical students and persons having similar academic background treatable.
\end{abstract}

\section{Introduction}

A high quality scale to measure depression, anxiety and stress of medical students is needed as they confront noteworthy academic, psychosocial, and existential stressors. Early intervention can be done if severity of above mentioned symptoms can be measured easily. But there is lack of such convenient tool in Bangla to measure rigorousness of above symptoms in a single setting. Translation of an internationally standard scale for measuring above symptoms can meet the need. Depression Anxiety Stress Scales (DASS) could be such an instrument. DASS was developed in English by researchers Professor SH Lovibond \& Prof PF Lovibond at the University of New South Wales Australia ${ }^{1}$ to measure depression, anxiety and stress among the respondents. It is a set of three self-report scales having 42 items designed to measure the negative emotional states of depression, anxiety and stress. ${ }^{2}$ Each of these is rated on a four-point Likert scale of frequency or severity of the participants' experiences over the last week with the intention of emphasizing states over traits. These scores ranged from 0 , meaning that the client believed the item "Did not apply to me at all", to 3 meaning that the client considered the item to "Applied to me very much, or most of the time". It is also stressed in the instructions that there is no right or wrong answers. The short-form version of the Depression Anxiety Stress Scales (DASS 21) created by the same researchers having 21 questionnaires can be used instead of full version of DASS. This valid ${ }^{3}$ set of instrument has seven questions for each subscale. A sum of the scores for the seven questions in each of the sub-scales completed by each participant is evaluated as per the severity-rating index. During the use of full version of DASS, for depression $0-9$ is normal while $10-13,14-20,21-27$ and $28+$ indicate mild, moderate, severe and extremely severe respectively. While measuring anxiety, 0-7 counted as normal but 8-9, 10-14, 15-19 and 20+ specify mild, moderate, severe and 
extremely severe correspondingly. Whereas $0-14$ is normal for stress although 15-18, 19- 25, 26-33 and $34+$ state mild, moderate, severe and extremely severe in that order. For short (21 -item) version, multiplication of sum by 2 is needed. ${ }^{4}$ DASS is a very widely used scale. Sixteen and six numbers of research articles already published which focused on DASS and DASS 21 respectively. ${ }^{5}$ There are several published studies showing that the DASS 21 has the same factor structure and gave similar results to the full DASS. ${ }^{4}$ DASS 21 had the advantage of taking only half the time to administer. In general, the full DASS is often preferable for clinical work and the DASS 21 is often best for research purposes. The items in the DASS 21 were selected on the basis of several criteria like good factor loadings, coverage of all subscales within each scale and item means that, DASS 21 scores for each scale should be very close to exactly half the full scale score. $^{6}$

With an objective to obtain a convenient scale to measure severity of depression, anxiety and stress among medical students, DASS 21 was translated into Bangla. A study on small sample size was also carried out to validate this Bangla version.

\section{Materials and methods}

Permission from the author of DASS (Prof Lovinbond) was taken to translate this. Translation process was according to guideline stipulated in US Census Bureau Guideline.7 Two forward and 2 backward translations were done in parallel by 2 medical and 2 language experts. After the reconcilement of the two forward and back translations, sentence revision was done by all experts involved in the translation in meetings. This Bangla version of DASS 21 was given to a panel of reviewer consisting of 2 Professors of Psychiatry, an Associate Professor of English and an Assistant Professor of Clinical Psychology at different universities. The format was kept similar to the original (English) version. At the end of this process, a harmonized Bangla version of DASS 21 was produced. Harmonized Bangla version was pre-tested on 10 students with an objective to identify any flaws in harmonized version. After pretesting, Bangla version of DASS $21 \mathrm{BV}$ was finalized. Validation of DASS $21 \mathrm{BV}$ was done by doing a pilot study to validate the DASS21 BV among first year medical students of Pabna Medical College, Pabna. Students who have got at least ' $A$ ' and another ' $A+$ ', in SSC and HSC in English was chosen for pilot study. 20 students filled up DASS 21 BV. After 3 days, 15 of them again filled up original DASS 21 (English). At the end of pre-test and reviewing by panel of experts, finalized Bangla version of DASS 21 (DASS-21 BV) was obtained. Analysis was done on the scores of 15 samples.

\section{Results}

Among the population, male and female 7 and 8 respectively $(M: F=1: 1.14)$ where age range was 18 20. Correlation for depression subscale was found 0.976 , anxiety subscale was 0.917 and stress subscale was 0.931 (Table 2). Correlation was significant at the 0.01 level (2-tailed). The result of reliability statistics were Cronbach's Alpha for total score 0.989 . Cronbach's Alpha for Depression, Anxiety and Stress subscales were $0.987,0.957,0.964$ respectively. The scores obtained by Bangla and English versions of the three subscales were almost similar (Figure 1-3).

Table 1: Correlation between DASS 21 BV and DASS $21(n=15)$

\begin{tabular}{|c|c|c|c|c|c|c|c|c|}
\hline & & $\begin{array}{l}\text { DASS } 21 \\
\text { depression } \\
\text { score }\end{array}$ & $\begin{array}{c}\text { DASS } 21 \\
\text { depression } \\
\text { severity }\end{array}$ & $\begin{array}{c}\text { DASS } 21 \\
\text { anxiety } \\
\text { score }\end{array}$ & $\begin{array}{c}\text { DASS } 21 \\
\text { anxiety } \\
\text { severity }\end{array}$ & $\begin{array}{l}\text { DASS } 21 \\
\text { stress } \\
\text { score }\end{array}$ & $\begin{array}{c}\text { DASS } 21 \\
\text { stress } \\
\text { severity }\end{array}$ & $\begin{array}{l}\text { DASS } \\
21 \text { total } \\
\text { score }\end{array}$ \\
\hline $\begin{array}{l}\text { DASS } 21 \\
\text { BV depression } \\
\text { Score } \\
\text { DASS } 21 \mathrm{BV} \\
\text { depression } \\
\text { severity }\end{array}$ & $\begin{array}{l}\text { Pearson } \\
\text { Correlation }\end{array}$ & $.976^{* \star}$ & $.965^{* *}$ & & & & & \\
\hline $\begin{array}{l}\text { DASS } 21 \\
\text { BV anxiety } \\
\text { Score }\end{array}$ & $\begin{array}{l}\text { Pearson } \\
\text { Correlation }\end{array}$ & & & $.917^{\star *}$ & & & & \\
\hline $\begin{array}{l}\text { DASS } 21 \text { BV } \\
\text { anxiety } \\
\text { severity }\end{array}$ & & & & & $.863^{* *}$ & & & \\
\hline $\begin{array}{l}\text { DASS } 21 \\
\text { BV stress Score }\end{array}$ & $\begin{array}{l}\text { Pearson } \\
\text { Correlation }\end{array}$ & & & & & $.931^{\star *}$ & & \\
\hline $\begin{array}{l}\text { DASS } 21 \mathrm{BV} \\
\text { stress severity }\end{array}$ & & & & & & & $.941^{\star \star}$ & \\
\hline $\begin{array}{l}\text { DASS } 21 \\
\text { BV total Score }\end{array}$ & $\begin{array}{l}\text { Pearson } \\
\text { Correlation }\end{array}$ & & & & & & & $.978^{* *}$ \\
\hline
\end{tabular}

\footnotetext{
** Correlation is significant at the 0.01 level (2-tailed).
} 
Comparison between Bangla \& English version (Depression sub scale)

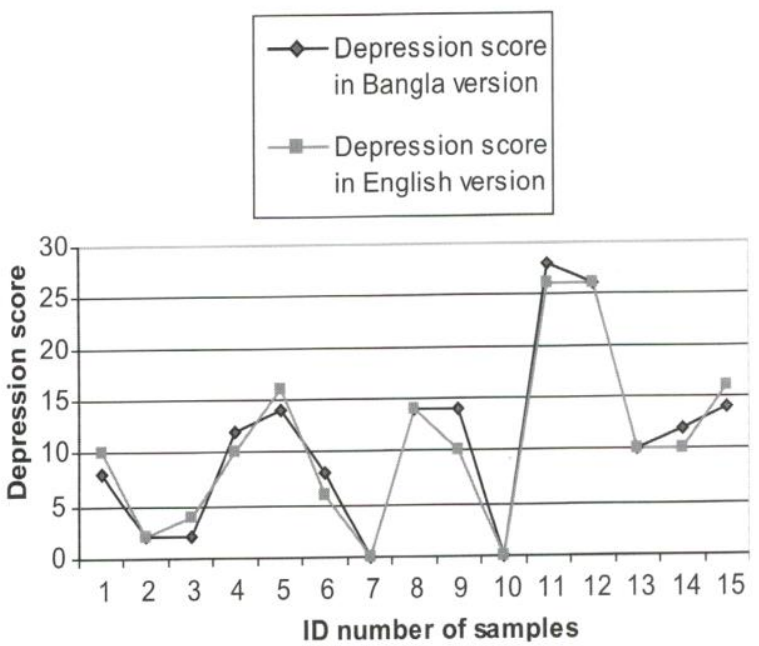

Figure 1: Comparison between Bangla \& English version of depression sub scale $(n=15)$

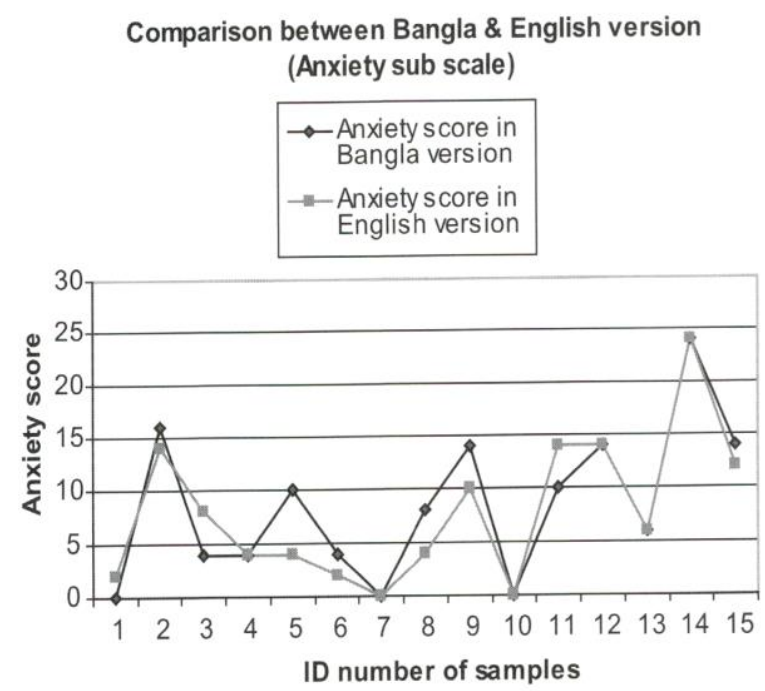

Figure 2: Comparison between Bangla \& English version of Anxiety sub scale $(n=15)$

comparison between Bangla \& English version (Stress sub scale)

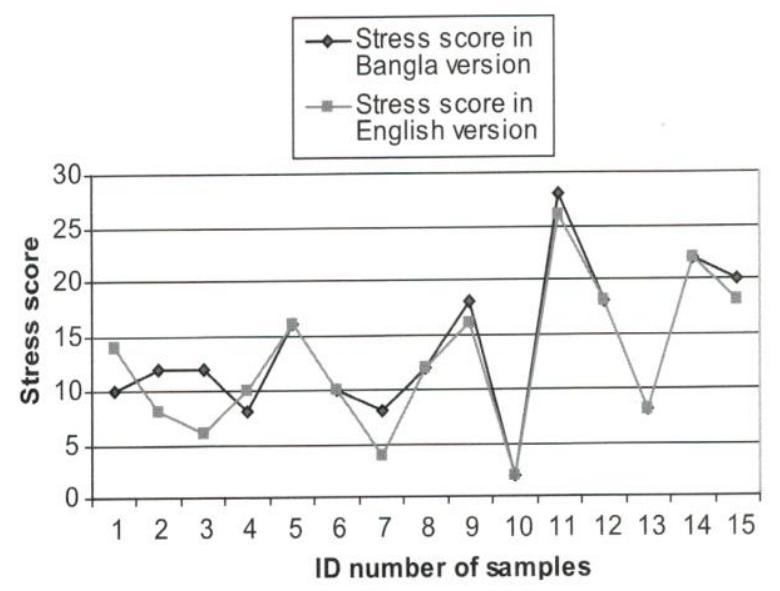

Figure 3: Comparison between Bangla \& English version of stress sub scale $(n=15)$

\section{Discussion}

US Census Bureau Guideline ${ }^{7}$ was followed to ensure that the translated version would be grammatically sounded and the terms used were correct. At the same time, meanings and contents of original DASS 21 were well preserved. Good translations were reflected by production of two English back translations which almost similar to original English version. Same guideline were used to translate DASS 21 into Malaysian language where there is similarity in religious cultural milieu with Bangladesh. ${ }^{8}$ DASS 21 Bangla version was accepted by the original author and given in DASS website. ${ }^{9}$ Till now, this scale was translated into 44 different national languages; such as: Arabic, Philipino, Hindi, Indonesian, Malaysian, Singhala, Taiwanese, Thai, Urdu, Vietnamese etc. ${ }^{10}$ Among them, 4 other countries of South Asian region translated DASS 21 into 6 tongues $^{10}$ where there are similarities in cultural ambiance with Bengalis.

Validation study of DASS 21- BV produced impressive correlation between Bangla and original English version. It was also proved to be very reliable tool as Cronbach's Alpha for total score were $>0.9$. It matched with the result of validated Bahasa Malaysia version of DASS 21.8 Bangla version of DASS 21 (DASS $21 \mathrm{BV}$ ) should be used in the studies among Bangla speaking population for measuring depression, anxiety or stress in place of original English version for better understanding of the respondents. Though medical students of Bangladesh might understand English, some statements of original DASS 21 seemed difficult to understand. As DASS 21 was previously used to measure depression, anxiety and stress among first year medical student in Moharastra province of India, ${ }^{11}$ this could be an expedient weighbridge to amount alike symptoms among Bangladeshi students.

Small sample size and sample taken from a single medical college were the major limitations of the study. Large sample with heterogeneous population could strengthen the validation process. However, as the samples were the 1st year MBBS students having lack of adequate medical knowledge but passed higher secondary level of education, this translated scale could be generally used among similar or higher academic background of medical as well as students or people of other disciplines.

Further research is needed for improvement and generalization of the Bangla version of the DASS 21 scale.

\section{Conclusion}

Validated Bangla version of DASS 21 can be used to measure severity of depression among medical students and persons having similar academic background. Further research is required for its generalization. 


\section{References}

1. Lovibond SH, Lovibond PF. Manual for the Depression Anxiety Stress Scales. 2nd ed. Sydney: Psychology Foundation of Australia; 1995. p. 1.

2. Lovibond PF, Lovibond SH. The structure of negative emotional states: comparison of the Depression Anxiety Stress Scales (DASS) with the Beck Depression and Anxiety inventories. Behav Res Ther 1995;33(3):335-43.

3. Henry JD, Crawford JR. The short-form version of the Depression Anxiety Stress Scales (DASS-21): construct validity and normative data in a large nonclinical sample. Br J Clin Psychol 2005;44(2):22739.

4. Gomez F. A Guide to the Depression, Anxiety and Stress Scale (DASS 21). Central and Eastern Sydney primary health networks. [Online]. [cited 2016 Sep 20]; Available from URL: https://www.cesphn.org.au/images/mental health/F requently Used/Outcome Tools/Dass21.pdf

5. Psychology Foundation of Australia. DASS publications: Depression Anxiety Stress Scales (DASS). [Online]. 2014 Nov 10 [cited 2016 Sep 6]; Available from URL: http://www2.psy.unsw.edu.au/dass//pub.htm

6. Psychology Foundation of Australia. DASS FAQ (Frequently Asked Questions): Depression Anxiety Stress Scales (DASS). [Online]. 2014 Nov 10 [cited 2016 Sep 6]; Available from URL: http://vwwv2.psy.unsw.edu.au/dass/DASSFAQ.htm
7. US Census Bureau. Census Bureau Guideline: Language Translation of Data Collection instruments and Supporting Materials (Working Paper). 2004 May 4. Washington DC: US Census Bureau; 2009.

8. Musa R, Fadzil MA, Zain Z. Translation, validation and psychometric properties of Bahasa Malaysia version of the Depression Anxiety and Stress Scales (DASS). ASEAN J Psychiatry 2007;s(2):s29.

9. Psychology Foundation of Australia. DASS translations: Depression Anxiety Stress Scales (DASS). [Online]. 2014 Nov 10 [cited 2016 Jun 21]; Available from URL:http://www2.psy.unsw.edu.au/dass/Bangla/Ba ngla.htm

10. Psychology Foundation of Australia. DASS translations: Depression Anxiety Stress Scales (DASS). [Online]. 2014 Nov 10 [cited 2016 Sep 6]; Available from URL: http://wvwv2.psy.unsw.edu.au/dass//translations.ht m

11. Vaidya PM, Mulgaonkar KP. Prevalence of depression anxiety \& stress in undergraduate medical students \& its correlation with their academic performance. IJOT 2007;39(1):7-10. 